Page, Amy Dellinger. (2007) "Behind the Blue Line: Investigating Police Officers' Attitudes Toward Rape." Journal of Police and Criminal Psychology 22 (1), 22-32. Published by Springer Verlag. The original publication is available at www.springerlink.com. (ISSN: 0882-0783) June 2007. DOI: $10.1007 / \mathrm{s} 11896-007-9002-7$

Keywords: Police officers | Rape myths | Attitudes toward rape

\title{
Behind the Blue Line: Investigating Police Officers' Attitudes toward Rape
}

\section{Amy Dellinger Page}

\begin{abstract}
The current study contributes to what is known about police officers' attitudes toward rape. A survey was administered to 891 sworn police officers in two states in the southeastern United States. The surveys were designed to assess police officers' acceptance of rape myths. It was hypothesized that police officers would be accepting of rape myths, which are inherently misogynistic. Attitudes toward rape were expected to vary according to educational attainment and experience with rape investigations, such that higher levels of education and more experience with rape investigations would lead to the rejection of rape myths. There was a significant difference in the acceptance of rape myths with varying levels of educational attainment and experience with rape investigations.
\end{abstract}

\begin{abstract}
ARTICLE
Men in American society are socialized to espouse "macho" beliefs and behavior. Connell (1987, $1995,2002)$ refers to this as "hegemonic masculinity," an idealized form of masculinity, emphasizing dominance, aggression, heterosexuality and a lack of emotion. Hegemonic masculinity promotes, but does not determine behavior that supports the traditional gender order. Rather, it shapes one's sense of reality and is modified to fit different situations (Messerschmidt 2000). In other words, hegemonic masculinity acts as a script for how men should behave and/or think in various situations.
\end{abstract}

In conjunction with being socialized as male or female in the larger society, there is also a socialization process that occurs in police culture. Holdaway (1983) discussed police culture as 
an informal structure of norms and values that operate within the more rigid hierarchy of the police organization. Police culture promotes a working "normative order." Herbert (1998) defined this normative order as a set of rules and practices that are centered on core values. Fielding (1994) noted that the police subculture represents almost pure hegemonic masculinity, stressing aggression, competition, rigid in-group/out-group distinctions, and promotion of a heterosexist atmosphere.

This subculture emerges, in part, from the occupational socialization of police recruits and the social isolation that often results from being a police officer. Police officers command a certain level of status and respect in American society. With this social position come certain expectations and perceptions of duty and even physical appearance. Police officers are expected to show physical and emotional strength. After all, they must fight crime, survive constant danger, protect the public from crime and natural disasters and remain emotionally strong in the face of human tragedy (Brown and Campbell 1994).

Police recruits are judged, therefore, on their appearance to recruiting officers in terms of how they will fare the public's visual inspection. The expectations of physical appearance, emotional strength and the ability to "fit in" within the masculine police subculture limit the diversity of police departments (Frewin and Tuffin 1998). This lack of diversity reduces the likelihood of exposure to individuals who do not fit the stereotypical male and female gender roles. Instead, police officers must adhere to the standards of masculinity. They must be "big, strong, tough and macho" (Frewin and Tuffin 1998: 177). Not only does the public hold police officers to this ideal masculine standard, but the policing subculture also maintains the importance of this standard. The socialization of police recruits not only focuses on the skills necessary for police work (e.g., firearms training, investigative techniques, etc.), but also on the values, beliefs and attitudes acceptable within the police subculture (Callan 1989; Schein 1992).

Martin (1989) noted that maintenance of sexist attitudes is often tied to police officers' occupational identities. Stereotypic displays of masculinity are expected and encouraged by public ideals and by other members of the police force. Socialization into police work, in combination with social isolation from the public, promotes a police "personality" and a subculture of policing. This subculture is protective of its identity and its members, who tend to share common attitudes, beliefs, and worldviews (McNamara 1999). 
In addition, Bradley, Walker, and Wilkie (1986) noted the strong resistance to change inherent in police culture. They regard this resistance to change as a form of pessimism, e.g. "whatever we do, things will not improve, we are prisoners of forces beyond our control." All of these factors indicate that police culture and individual police officers maintain rigid attitudes about the roles and actions of men and women in society. These strict role definitions may contribute to a general police culture that is negative toward women and facilitate the continued acceptance of rape myths.

Research on female police officers suggests they are victims of sexual discrimination. They are often sexually harassed and do not receive equal credit for their work (Daum and Johns 1994). Timmins and Hainsworth (1989) found that sexual harassment and discrimination were far more prevalent than expected among police officers, and that harassment was supported and carried out by supervisory officers. Martin (1989) suggested that a sexist atmosphere often causes female officers to withdraw and to fail to build interpersonal relationships necessary for mentoring and sponsorship.

Police work is characterized by its own occupational beliefs and values that are generally shared by officers in the United States (Herbert 1997). As members of a subculture, police officers import many values and beliefs from the broader society in which they live. For example, the conservative and masculine disposition of officers may be a reflection of the type of individuals drawn to police work (Roberg et al. 2004). These attitudes, beliefs and norms are reinforced through communication and association with more experienced police officers (McNamara 1999).

\section{Police Officers and Education}

Several studies suggest that police officers with a college education are more aware of social problems and are more accepting of traditionally oppressed groups (Weiner 1976). These officers are also generally more professional and ethical in their attitudes and behavior (Tyre and Braunstein 1992; Truxillo et al. 1998). Other studies indicate that police officers with higher levels of education are less authoritarian than those with less formal education (Smith et al. 1968; Smith et al. 1970). 
Smith and Aamodt (1997) speculated that the benefits of a college education may not become apparent until paired with on-the-job experience, indicating that education is only one tool and should be used in conjunction with training and experience. Another study assessing the relationship between attitudes and performance found that officers with "college degrees had the most open belief systems and highest levels of job performance, indicating that college-educated officers were better able to adapt to the complex nature of the police role" (Roberg 1978: 344). These findings indicate that the overall experience of a college education may prove beneficial in broadening police officers' attitudes and improving performance, including the use of discretion.

The criminal justice system institutionalizes discretion when deciding which behavior(s) will be criminalized and the level of punishment to attach to each crime (Schulhofer 1988). The level of discretion employed by individuals who work within the criminal justice system varies widely. Prosecutors have practically unlimited discretion to charge an individual with a crime and to determine the charges themselves. They also may choose to offer a plea bargain for a lesser offense or sentence. Police officers have discretion in choosing which cases to investigate and, in some jurisdictions, to determine the charges that result from the investigation. Police officers have a discernable amount of power over others' lives. They constantly make decisions about whether to pull someone over for speeding, how to handle a public disturbance, whether to arrest someone or let them go with a warning. Given the discretionary power of police and the masculine ideals that pervade police culture (Murrell and Lester 1979), one would expect this rigid adherence to gender roles to constrain the investigation and charging of sexual assault offenders as well as the acceptance of rape myths.

Agents of the criminal justice system do not operate in a vacuum, of course, but are guided by laws and procedures. Rape laws underwent significant reform in the United States beginning in 1975. Changes included expanding the definition of rape, limiting the corroboration requirement and enacting rape shield laws: that is, limiting the admissibility of the victim's sexual history. Recent research on the acceptance of rape myths shows that the public and still largely endorses rape myths blame the victim and excuse the offender, despite recent reforms (Abbey and Harnish 1995; Mori et al. 1995; Ward 1995; Kopper 1996; Johnson et al. 1997).

\section{Police Officers' Attitudes Toward Rape}

Although we have some knowledge of police officers' attitudes toward rape prior to these recent rape law reforms, it is unclear whether reforms have affected police officers' attitudes or 
behavior. The existing research on police officers shows that they tend to hold rape victims to a higher standard of evidence and decorum than they do other victims of crime (Galton 1975; Hazelwood and Burgess 1995). Like prosecutors, police officers apparently rely on legal as well as extralegal factors when assessing rape complaints. Hazelwood and Burgess (1995) found that police officers have an image of an ideal rape and an ideal victim of rape. All rapes and victims are compared to this ideal. They stated that when assessing a rape complainant's story, police officers look for quality, consistency, and the existence of corroborating evidence. Galton (1975) found that police officers expect more consistency in a rape complainant's story than they do from victims of any other crime.

Police officers also consider specific details of the victim's background and behavior to be important. In Hazelwood and Burgess' (1995) study, a case where the victim was forced into a situation or location was seen as a stronger case than where the victim went freely, even if she was unaware of the impending danger. They further found that the existence of a relationship between the victim and offender affected police attitudes about the merits of a case. Police officers defined a strong rape case as one in which the victim and offender had no prior relationship and where an age difference existed. Offender characteristics, such as a prior criminal record, were important to police officers, although arguably not as important as victim characteristics (Hazelwood and Burgess 1995). Although a prior criminal record would seem important, this information is not always admissible in court for subsequent offenses. The victim's background and characteristics, however, are always up for interpretation by criminal justice agents.

Several studies have compared police officer attitudes with the attitudes of citizens, other criminal justice employees and/or social service personnel. These studies find that police officers' attitudes differ in meaningful ways from those of citizens and social service personnel.

Field (1978) used a quantitative survey designed to assess attitudes toward women and rape along with knowledge of rape laws to patrol police officers, community members, female counselors in rape crisis centers, and committed rapists in a state hospital. He found police officers' attitudes toward rape to be more similar to rapists' attitudes than to the attitudes of citizens or rape crisis counselors. Personal knowledge of a raped woman, contact with and interviews with rape victims were not significantly correlated with attitudes toward rape. Police officers who had not participated in rape training programs were more likely than those who had participated to see resistance as one of the victim's primary responsibilities. 
Feldman-Summers and Palmer (1980) administered closed-ended surveys to police officers, staff members of two rape crisis counseling centers, prosecuting attorneys and superior court judges in Seattle, Washington. The surveys contained questions about beliefs regarding the causes of rape and beliefs about certain rape complaints being "true" or "false," and circumstances pertaining to each type of report. Group responses differed markedly on the perceived causes of rape. Social service personnel attributed rape to social factors (e.g., "men have been taught that when a woman says 'no' she means 'yes'") and the overall socialization of men (e.g., "men have been taught that rape is acceptable" and "rape in an inevitable part of human nature"). Criminal justice personnel, however, viewed the cause of rape as a result of women's poor judgment, dress, and demeanor.

The groups also differed on their beliefs about rape complaints. Social service personnel believed that approximately 70 percent of rape complaints reflect "true" rapes, with the assailant correctly identified. Police officers stated that only 36 percent fell into this category. Both groups agreed that very few innocent people are convicted of rape. Although the groups disagreed on the percentage of credible rape complaints, there were no statistically significant differences on the characteristics that comprise credible complaints. Both social service personnel and criminal justice personnel cited the following characteristics of credible rape complaints: the victim has physical injuries, waits fewer than 48 hours to report the crime, is consistent in her account of the rape, is willing to take a lie detector test, does not engage in premarital or extramarital relations, and is seen by others as having been raped. It is possible that the lack of statistical significance stems from the low number of participants comprising each group (Feldman-Summers and Palmer 1980).

Similar to Field (1978) and Feldman-Summers and Palmer (1980), Brown and King (1998) compared police officers' attitudes toward women and rape to those of college students. Each group consisted equally of women and men. They administered a closed-ended questionnaire containing indexes to assess hypermasculinity, hyperfemininity, attitudes toward women, general attitudes toward rape, and the acceptance of interpersonal violence. In general, women were significantly more likely to have positive attitudes toward women, and were significantly less accepting of rape myths and interpersonal violence (e.g., "being roughed up is sexually stimulating to many women"). Male and female students were not significantly different in their acceptance of rape myths and interpersonal violence, but female police officers were significantly less accepting of rape myths than were male police officers. Furthermore, they suggested that the differences in attitudes among male and female police officers may have to do with a greater adherence to gender identity than occupational identity when considering rape myths. 
LaFree (1989) studied the processing of rape cases in Indianapolis during the 1970s at various points in the criminal justice system (i.e., in encounters with police, prosecutors, courts and juries). He and other researchers (Field 1978; Burt 1980) contend that criminal justice agents share general sexist beliefs about the crime of rape and rape victims. The more a victim or the characteristics of the assault deviate from this preconceived idea, the less likely police and prosecutors are to devote extensive time and energy to processing the case (LaFree 1989; Hazelwood and Burgess 1995).

LaFree's (1989) research in Indianapolis showed that police were less likely to make an arrest when the victim did not conform to sex role stereotypes. Examples of such "nonconformity" included going to a bar without a male escort, drinking, hitchhiking, willingly entering the offender's property or engaging in premarital or extramarital sex. Although these factors influenced police decisions to arrest, they did not influence the victim's decision to press charges. Police were less likely to make an arrest if the victim delayed reporting the crime to the police.

Campbell (1995) conducted a multi-method study with 53 police officers from a mid-sized city in the Midwest and 38 officers from a large Midwestern university. Through both qualitative interviews and surveys, officers were questioned about their work environment and their attitudes about date rape, whether their attitudes had changed since joining the force and if so, how. Sixty-two percent of the officers claimed that they now view date rape more seriously and that they have more sympathy for the victim than when they first joined the police force. More than a third of the officers indicated no change in their attitudes. Fourteen percent noted that their departments do not treat rape cases seriously enough.

In a follow-up article to Campbell's 1995 study, Campbell and Johnson (1997) reported how police officers in the aforementioned sample defined rape/sexual assault in their own words. Three "clusters" of definitions emerged from the results, with each cluster comprised of conceptually similar definitions. The first cluster, offered by thirty-one percent of the sample, was named the "Consent Definition of Rape." This group defined rape in terms of penile penetration and lack of consent. However, consent was not part of the legal definition of rape in the state they studied. Only thirty percent of this cluster mentioned the use of force, which was a defining feature of the state statute. The second cluster, given by nineteen percent of the sample, was the "Force Definition of Rape." It defined rape in roughly the same terms currently 
comprising the legal definition of rape in the officer's state. These factors included penetration (84 percent), the use of force (95 percent) and the threat of force (58 percent).

The third cluster, offered by the remaining fifty percent of the sample, provided a "Mixed Definition of Rape." This definition contained old and new legal components along with rape myths. The mixed definition focused on penetration (42 percent), rape as the assailant's sexual gratification (40 percent) and consent (51 percent). However, only penetration was part of the legal definition in the state where the research was conducted. Consent was not part of the legal definition. Officers who provided a "Mixed Definition of Rape" attributed more blame to victims and were more conservative in their views about women, as measured by Spence, Helmreich and Stapp's (1973) Revised Attitudes toward Women Scale, than were those providing a "Consent Definition" or a "Force Definition of Rape." It is not known if these beliefs and opinions translated into actual behavioral responses in the treatment of rape cases and victims of rape (Campbell and Johnson 1997).

The results of these studies indicate that police officers are generally accepting of rape myths: that is, if the victim adheres to stereotypic feminine behavior and the alleged rape adheres to characteristics of an ideal rape, the officer is more likely to deem the victim's statement as credible and investigate the case.

However, LeDoux and Hazelwood (1985) conducted the largest study ever of police officers' attitudes about rape and found contrary evidence. Using county and municipal law enforcement agencies that contribute to the Uniform Crime Report, the researchers surveyed 2,170 sworn officers. Unlike any other study assessing police attitudes about rape, LeDoux and Hazelwood reported a low endorsement of rape myths among police officers. The officers viewed rape victims as innocent and disagreed that women should have to prove they did not encourage the rape through their behavior. They strongly disagreed with statements indicating that a raped woman is not truly a victim. Police officers seemed somewhat perplexed about the motivations of the rapist. While officers did not agree that rapists are "normal," neither did they agree rapists are mentally ill. They believed that rapists are sexually frustrated and that rape is a sex crime, but disagreed that rapists have an "uncontrollable desire for sex" or that they "commit rape for sex." The police officers did not consider rape an expression of the rapist's manhood, but they did see the crime as an exercise of the rapist's power over women. 
Although existing research suggests that police officers endorse rape myths, even after exposure to training (Gottesman 1977; Muram et al. 1995; Lonsway et al. 2001), few studies have assessed police officers' attitudes since the enactment of rape law reforms. Most studies used small sample sizes (i.e., under 100) with the exception of LeDoux and Hazelwood (1985), whose study used the only national sample of law enforcement personnel. The purpose of the current study was to contribute further understanding of how police officers view the crime of rape and its victims post reform.

\section{Rape Myths}

Burt (1980) was among the first to empirically study "rape myths," which refer to the stereotypical and empirically incorrect beliefs that an individual holds concerning rape, rapists and the victims of rape. Rape myths may provide a justification (e.g., she seemed to like it) or an excuse (e.g., that was bad, but I'm not [wholly] responsible) for the (male) rapist's behavior (Scott and Lyman 1968). That is, responsibility is either displaced from perpetrators on the idea that they surpassed the level of "controllable" sexual stimulation and could no longer be held accountable for their actions (Bart 1979) or female victims and potential victims are cast as the responsible party. They are instructed to be aware of male propensities and take action (or remain passive) to avoid rape. Women are told not to dress provocatively so as not to arouse the presumed uncontrollable sexual urges in men. They are also instructed not to go out at night alone. Rather, they should keep protection (a man) with them at all times if possible. All of these messages warn of the looming possibility of rape, which restricts the movement of women and to a certain extent dictates how, when and where women travel and congregate (Stanko 1997).

Burt (1980) found that individuals with higher levels of educational attainment accepted fewer rape myths than individuals with lower levels of educational attainment. Studies have also shown that college-educated police officers are more attuned to social problems (Weiner 1976; Carter and Sapp 1990) and education has a positive effect on job performance (Sanderson 1978; Truxillo et al. 1998; Wilson 1999; Lersch and Kunzman 2001). Given these findings, it was hypothesized that police officers with higher levels of education would accept fewer rape myths.

It was further hypothesized that police officers with more experience working on rape investigations would accept fewer rape myths. Rape myths are stereotyped beliefs about rape and victims of rape. One would expect that the more contact police officers have with victims who do not confirm the rape myth, the less believable the myth would become to them. 


\section{Methods}

The current study was designed to assess police officers' attitudes using revised measures of rape myths using a closed-ended questionnaire. Demographic information was also collected and used to make within-group comparisons.

Participating agencies were identified using a snowball sampling method. A colleague who works with a private training academy supplied the names of several Chiefs of Police and Sheriffs in two states in the Southeastern United States who were willing to participate in the study. Those individuals, in turn, supplied additional names of Chiefs of Police and Sheriffs. I contacted all referred Chiefs of Police, Sheriffs or contact persons and requested assistance. All police departments willing to participate were included in the population. Seven police departments and four sheriff's departments agreed to participate in the study. Four police and sheriff's departments declined, citing time constraints or the belief that few officers would be willing to participate. 1

\section{Procedures}

A census of the eleven identified police departments and sheriff's offices was conducted, meaning that every police officer in the department was provided a survey packet. These agencies were located in two states in the Southeast United States. Participants were told that their participation in the study was voluntary and that they could elect not to complete the survey with no career, occupational or training repercussions since no one would know whether or not they participated. The participants were advised that all their responses would remain anonymous. The departments were also notified that neither individual nor department names would be referenced in any written report. The officers were informed that the research staff would not have access to names of individuals, nor would any characteristics of the departments be released. Whereas this sample is not necessarily representative of police officers throughout the United States, findings will shed light on the attitudes of sworn police officers in the surveyed areas. This study represents a census in that every member of the identified target sample had the option of completing a survey. Those who responded to the survey represented one-third of the population of interest. 
Survey packets were mailed to the participating police departments and sheriff's offices for distribution. Each survey packet contained a statement of anonymity, a questionnaire and a blank envelope. The questionnaire stated that consent to participate in the study was given by returning the completed survey. The individual police officers were instructed to complete the survey, place it in a blank envelope and return the sealed envelope to a drop box. Police officers also had the option of placing a blank survey in an envelope and placing it in the drop box. The contact person collected the sealed envelopes from the drop box and mailed them to the researcher. Placement of completed surveys in the sealed envelopes ensured the anonymity of responses, as the researcher did not have access to any names of sworn officers.

\section{Survey Instrument}

The survey instrument was designed to measure police officers' perspectives on sexual assault and included two attitudinal scales: (1) a Rape Myth Acceptance Scale-Revised (RMA-R); and (2) an original Victim Credibility Scale (VCS). The RMA-R was adapted from Burt's (1980) rape myth acceptance scale. Her scale contained 14 items and assessed levels of endorsement of myths about rape, rapists and victims of rape. A rape myth is a stereotyped belief about rape that places blame for the crime on the victim. Burt's scale was altered by removing items that seemed superfluous or outdated. The "hitchhiking" item was deleted because this practice no longer appears as common, at least among women, as it was during the early 1980s. The "stuck-up" and "drunk at a party" items were deleted both because they were double-barreled items and their meaning was unclear. Several other original items that were double-barreled were made into separate items or shortened. For example, the item "When women go around braless or wearing short skirts or tight tops, they are just asking for trouble" was shortened to "Women who dress provocatively are inviting sex."

In addition to the aforementioned changes, several items that were not legally relevant to the study of rape at the time of Burt's (1980) study were added to the scale. For instance, the item "Any man can be raped" was included in the revised scale. When Burt created her RMA, rape was defined in criminal law as a crime against a woman. Rape law reforms led to the adoption of gender-neutral language in some states, making it legally possible for a male to be raped, although the FBI still identifies only women as victims of rape.

\section{Factor Analysis}

Factor analysis is a technique used to determine groupings of similar constructs. A correlation matrix is created for groupings of interrelated quantitative variables, or "loadings." For each 
grouping, variables within each factor are more highly correlated with one another than with variables in another grouping. Factor analysis using principal components revealed that several items adapted from Burt's (1980) rape myth acceptance scale, did not "load with" the other items in the revised scale. That is, they did not appear to measure the same constructs as the items that did "load." They were removed from the scale and treated as separate items. The removed items were "In your opinion, what percentage of women who report a rape are lying?"; "In your opinion, what percentage of reported rapes are by women who discovered they were pregnant?"; and "In your opinion, what percentage of reported rapes are by women who want to provide an excuse for having a sexually transmitted disease such as HIV, AIDS or herpes?” These items used the following responses: "76 to 100 percent, 51 to 75 percent, 26 to 50 percent, 10 to 25 percent or Less than 10 percent."

The Revised Rape Myth Acceptance Scale (RMA-R) consisted of ten items (see Table 1). The response set for the scale varied from "Strongly Disagree" to "Strongly Agree" and used a fivepoint scale. High scores on the RMA-R indicate endorsement of rape myths. The RMA-R had a Cronbach $(\alpha)$ coefficient of 0.75 .

Table 1 Item percentages for the rape myth acceptance scale-revised $(N=869)$

\begin{tabular}{|c|c|c|c|c|c|}
\hline Item & SD & $\mathbf{D}$ & NDA & A & SA \\
\hline Any woman can be raped. & 2.1 & 2.4 & 1.5 & 30.6 & 62.6 \\
\hline Any victim can resist a rapist if s/he really wants to. & 22.3 & 35.4 & 18.5 & 16.6 & 6.1 \\
\hline Women who dress provocatively are inviting sex. & 20.3 & 33.3 & 25.4 & 15.6 & 4.5 \\
\hline Any man can be raped. & 5.9 & 13.5 & 13.4 & 40.9 & 25.5 \\
\hline Many women secretly wish to be raped. & 52.6 & 26.8 & 15.6 & 2.5 & 1.6 \\
\hline A woman is responsible for preventing her own rape. & 28.4 & 35.0 & 21.5 & 11.9 & 2.0 \\
\hline $\begin{array}{l}\text { A woman that goes to the home of a man on their first date implies } \\
\text { she is willing to have sex. }\end{array}$ & 32.7 & 43.8 & 16.6 & 4.4 & 1.6 \\
\hline Women falsely report rape to call attention to themselves. & 10.0 & 30.9 & 38.4 & 17.1 & 2.6 \\
\hline $\begin{array}{l}\text { In the majority of rapes, the victim is promiscuous or has a bad } \\
\text { reputation. }\end{array}$ & 19.3 & 46.0 & 27.6 & 5.9 & 0.7 \\
\hline $\begin{array}{l}\text { It is a woman's fault if she makes out with a guy and lets things get } \\
\text { out of hand. }\end{array}$ & 20.2 & 52.7 & 19.3 & 6.1 & 1.0 \\
\hline
\end{tabular}

Note. SD = Strongly Disagree, $\mathrm{D}=$ Disagree, $\mathrm{NDA}=$ Neither Disagree or Agree, $\mathrm{A}=$ Agree, $\mathrm{SA}=$ Strongly Agree.

The Victim Credibility Scale (VCS) was designed to measure how believable a certain victim would be to individual police officers. For instance, would an alleged victim be more believable if s/he was a teenager or an elderly person? The scale serves as a more specific measure of rape 
myth acceptance. Whereas the RMA-R asked about general attitudes toward rape, the VCS asked how believable rape victims are who have varying characteristics. This scale was adapted from a question on Burt's (1980) Rape Myth Acceptance Scale that did not factor load with other questions. The items were reworked to include variations in age, sex, professional and marital status (see Table 2). The scale used a five-point scale ranging from "Very Unlikely" to "Very Likely." The VCS had a Cronbach $(\alpha)$ coefficient of 0.81 .

Table 2 Item Percentages for the Victim Credibility Scale $(\mathrm{N}=866)$

\begin{tabular}{|l|l|l|l|l|l|l|}
\hline Item & VU & U & NUL & L & VL \\
\hline $\begin{array}{l}\text { A person comes to you and claims a rape has occurred. How likely } \\
\text { would you be to believe the statement if the person was: }\end{array}$ & & & & \\
\hline Someone you know. & 1.0 & 1.2 & 9.5 & 42.3 & 44.7 \\
\hline A virgin. & 1.3 & 3.3 & 19.9 & 48.0 & 25.9 \\
\hline A teenager. & 1.0 & 3.3 & 26.2 & 52.7 & 15.3 \\
\hline An elderly person. & 0.9 & 2.1 & 12.9 & 43.5 & 38.4 \\
\hline A prostitute. & 14.5 & 29.6 & 29.3 & 19.1 & 5.8 \\
\hline A man. & 4.3 & 16.7 & 29.7 & 34.9 & 12.7 \\
\hline A professional woman. & 1.0 & 1.2 & 20.9 & 58.1 & 17.3 \\
\hline A married woman accusing her husband. & 4.8 & 14.1 & 37.0 & 33.3 & 9.2 \\
\hline
\end{tabular}

Note. $\mathrm{VU}=$ Very Unlikely, $\mathrm{U}=$ Unlikely, $\mathrm{NUL}=$ Neither Unlikely or Likely, $\mathrm{L}=$ Likely, $\mathrm{VL}=$ Very Likely.

\section{Analytic Techniques}

Data for the scales were first tested for normality using the Shapiro-Wilk statistic. Results showed that none of the scales were normally distributed, meaning that parametric statistics could not be used to test the hypotheses. Given the construction of the response scales - ranging from "Strongly Disagree" to "Strongly Agree" with "Neither Disagree or Agree" as the midpoint - one would not expect the data to be normally distributed. Measures of attitudes toward rape typically elicit definitive opinions in one direction or another. They are not neutral in nature. Therefore, one would expect data to be loaded on either end of the response scale.

The Spearman Rank Correlation, the Kruskal-Wallis test and the Mann-Whitney test were used to test the hypotheses. These non-parametric statistics do not make assumptions about the distribution of data and are also less sensitive to uneven groupings of data. 


\section{Results}

The study had a 30.7 percent response rate, meaning that data were available for approximately thirty percent of the identified population. A total of 2,898 survey packets were distributed to the population and 891 completed surveys were returned.

Eighty percent (716) of respondents were male and seventeen percent (150) were female. Three percent (27) of respondents chose not to identify their gender. Sixty-four percent (571) of respondents identified their race as Non-Hispanic or White, twenty-four percent (213) identified themselves as African American, one percent (10) as Asian American or Pacific Islander, two percent (18) as Native American and one percent (8) as Latino/a or Hispanic. Three percent (27) classified their race as Other and five percent (44) chose not to identify their race. Nationally, local law enforcement personnel are comprised of eleven percent female, twelve percent African American, nine percent Hispanic and three percent who classify their race as Other (U.S. Department of Justice 2006).

In terms of educational attainment, eight percent of respondents (78) held a high school diploma or GED. Forty-one percent (366) had attended some level of college, but had not obtained a degree. Fifteen percent (128) earned an Associates degree and twenty-nine percent (262) earned a Bachelors degree. Three percent (23) of respondents earned a Masters degree and three percent (29) chose not to disclose their highest level of educational attainment. The respondents ranged in age from twenty-two to sixty-seven years, with the mean age being 37.

In general, the police officers studied had a wide range of investigative experience specific to rape. The majority of the officers (49\%) had little experience, meaning they had worked five or fewer rape investigations in the course of their careers. However, a sizable minority (15 percent) had worked between six and ten rape investigations (128) or more than twenty-one rape investigations (106). 


\section{Attitudes Toward Rape}

The majority of police officers agreed "any woman can be raped" (93 percent) and "any man can be raped" (66 percent) (see Table 1). The majority of officers also disagreed with statements that would blame the victim, such as "in the majority of rapes, the victim is promiscuous or has a bad reputation" (65 percent) or "many women secretly wish to be raped" (79 percent). This item analysis would indicate that police officers might be less accepting of rape myths than was found in earlier studies.

Table 2 shows the item percentages for the VCS. In general, police officers were most likely to believe someone they know ( 87 percent), a virgin (74 percent), an elderly person (82 percent) or a professional woman (75 percent) who claimed s/he was raped. Forty-four percent of the officers were unlikely to believe a prostitute who claimed s/he was raped.

It was hypothesized that police officers with higher levels of educational attainment would accept fewer rape myths. The Kruskal-Wallis test was run to see if there were differences between levels of educational attainment and scores on the RMA-R. There was a significant difference between levels of educational attainment and RMA-R scores $(\chi 2=16.507, p<.05)$.

The Mann-Whitney test was used to determine whether certain levels of educational attainment were significantly different from other levels for scores on the RMA-R. Police officers who had a high school diploma or GED were significantly different from those who had an Associates degree $(\mathrm{U}=3822, \mathrm{p}<.05)$, such that officers with a high school diploma or GED scored significantly higher on the RMA-R than did officers with an Associates degree. Police officers with a high school diploma or GED also scored significantly higher than did those who had a Bachelors degree $(\mathrm{U}=7056, \mathrm{p}=.001)$. Finally, police officers with a high school diploma or GED differed significantly from those with a Masters degree $(U=485, p=.001)$ : specifically, officers with a high school diploma or GED scored significantly higher on the RMA-R than did those with a Masters degree. The Mann-Whitney test was also computed to test for significant differences between other levels of educational attainment and scores on the MSS (i.e., some college education versus Associates degree and Associates degree versus Bachelor degree). None of these comparisons yielded statistically significant differences.

It was also hypothesized that police officers who had more experience working on rape investigations would accept fewer rape myths. Rape myths are stereotyped beliefs about rape and victims of rape. Therefore, one would expect that the more contact a police officer has with 
victims who do not confirm the rape myth, the less likely the officer would be to accept the myth. The Kruskal-Wallis test was used to determine if police officers with different levels of experience conducting rape investigations differed in their acceptance of rape myths. There was a significant difference between levels of experience with rape investigations and scores on the RMA-R in the expected direction $\left(\chi^{2}=18.569, \mathrm{p}=.001\right)$. Police officers who had worked five or fewer rape investigations scored significantly higher on the RMA-R scale than police officers who had worked more than twenty-one (21) rape investigations $(U=12936, p<.001)$. No other group comparisons, such as between officers who had worked between six and ten rape investigations and those who had worked between eleven and fifteen rape investigations, were significant.

\section{Victim Credibility}

The Victim Credibility Scale (VCS) provided a more specific measure of rape myth acceptance than the RMA-R. While police officers may view the crime of rape as a significant and awful crime, they may still discount the experiences of specific victims. For instance, the vast majority (94 percent) of police officers agreed on the RMA-R that any woman can be raped, yet when asked about victim credibility on the VCS, nineteen percent were unlikely to believe a married woman who claimed she was raped by her husband and forty-four percent were unlikely to believe a prostitute who claimed s/he was raped. Only five percent of police officers were unlikely to believe a virgin and just two percent were unlikely to believe a professional woman who claimed she was raped. This contrasting information suggests that it still does, in fact, matter what "kind" of woman claims she was raped. Likewise, sixty-seven percent of respondents agreed that any man could be raped. However, when asked how likely they would be to believe a man who claimed he was raped; forty-eight percent of respondents indicated they would believe the person.

Another aspect of victim credibility was tapped by three questions that did not factor load with the RMA-R or the VCS. These questions asked the police officers what percentage of rape victims they believe are lying about being raped, are trying to explain a pregnancy, or are trying to explain a sexually transmitted disease. The majority of police officers believed less than twenty-five percent of rape allegations are due to women lying (72 percent), trying to cover up a pregnancy ( 83 percent) or trying to provide an excuse for a sexually transmitted disease (81 percent). 


\section{Gender Differences Among Police Officers}

Female police officers differed significantly from male police officers on scores on the RMA-R $(\mathrm{U}=33506.5, \mathrm{p}<.001)$, such that male officers endorsed more rape myths than did their female counterparts. There was also a significant difference between male and female police officers on the VCS $(\mathrm{U}=37125.5, \mathrm{p}<.001)$, such that female officers were more likely to believe victims with the provided characteristics who claimed they were raped than male police officers.

Police officers with different education and work experiences and of different genders also differed significantly in their acceptance of rape myths, as assessed by the RMA-R. Officers with higher levels of educational attainment were less likely to endorse rape myths, as were officers with more experience conducting rape investigations. Conversely, police officers with lower levels of educational attainment and less experience conducting rape investigations were more accepting of rape myths. It should be noted, however, that police officers with no experience with rape investigations were left out of the statistical analysis.

\section{Discussion}

Despite the differences in scores on the RMA-R, it is quite possible a social desirability effect was operating. Rape is a highly charged and sensitive topic, especially when discussed in an occupational environment like policing. Even though officers were assured anonymity of their responses, my name and contact information were provided on the survey. Therefore, participants were aware of my gender and this knowledge may have influenced their responses.

One measure of a social desirability effect came from comparing scores on the Victim Credibility Scale (VCS) and the RMA-R. Police officers endorsed items stating that any man (67 percent) or any woman (94 percent) can be raped. However, when questioned further about the credibility of certain hypothetical victims, they were less likely to believe that a man, a prostitute or a married woman had been raped. It is apparent that despite responses to the contrary on the RMA-R, it does indeed matter what kind of person alleges rape. 


\section{Conclusion}

The current study contributes to our knowledge of how police officers view the crime of rape and its victims since inception of rape law reforms. As with any research, this study was prone to certain limitations. For example, participants were aware that I am a woman (as my name and contact information were listed on the survey) and a strong social desirability element may have persisted given the nature of the topic. Rape is a difficult and sensitive topic to discuss, especially with individuals in the context of their work environment. Police officers operate in a closed environment, as do members of any organization (McNamara 1999). They may have felt an obligation to portray that organization in a favorable light. This sense of obligation, along with wanting to portray themselves individually in a positive way, may have influenced their responses.

The findings of this study are also limited in terms of generalizability. Snowball sampling is not as beneficial in terms of providing a representative sample as random sampling, nor was this a national sample. However, national demographic data for local police departments indicates that a larger number of women and African Americans comprise the current sample than are represented in the national population of police officers.

This study broadens our understanding of how police officers in the southeast United States view the crime of rape and its victims. It is possible that while police officers generally view the crime of rape as a serious one, they may discount individual rape victims and cases. Rape has been defined by the public and by law enforcement agencies as a significant social problem and, therefore, police officers may also think of rape as a serious offense. Hence, responses to the RMA-R, where police officers did not highly endorse rape myths. Yet, the officers may still discredit individual victims and allegations of rape. This was supported by the contradictory responses to the RMA-R and the VCS. Many officers, who were not generally supportive of overall rape myths, were still suspicious of individuals who did not fit the ideal of a "genuine" victim. They also placed the number of false reports of rape much higher than the known percentage of false reports $(4 \%)$.

Attitudes and beliefs held by those new to law enforcement may be especially important, as they have grown up in a time where women experienced more equality and rape law reforms have existed in some form. The ambiguity of certain responses on the RMA-R and VCS indicate a strong need for continued education on the topic of rape, especially for those entering and currently in law enforcement. Education related to the topic of rape should be well planned and assessed for its effectiveness. 
Research suggests that college-educated police officers are more likely to take leadership roles within their department (Krimmel 1996), to attain promotions (Cohen and Chaiken 1972; Roberg and Laramy 1980) and to be innovative in their job performance. Higher education would thus seem to coincide with more flexible attitudes. However, some research on higher education finds that police officers with more education are less satisfied in their jobs and are more likely to quit law enforcement (Cohen and Chaiken 1972; Weirman 1978; Mottaz 1983). It is possible that these officers report less satisfaction and leave their jobs prematurely because their attitudes do not fit with the larger police culture. Since police culture is typically masculine and authoritarian, it is possible that police officers with more egalitarian beliefs would be less satisfied in this type of environment. It would seem that training might also be beneficial in altering attitudes for the sake of retaining better-educated officers.

The results of this study suggest that designating college-educated and experienced police officers for special sexual assault units would be beneficial to departments and victims alike, as police officers with any level of college education were less supportive of rape myths. Officers with more rape investigation experience would train newer officers, thereby altering the current informal occupational socialization process. Since college-educated and experienced officers are less likely to hold hegemonic masculine attitudes toward women and rape, they are more likely to positively influence other officers' attitudes.

\section{References}

Abbey A, Harnish RJ (1995) Perceptions of sexual intent: The role of gender, alcohol consumption, and rape supportive attitudes. Sex Roles 32:297-313

Bart PB (1979) Rape as a paradigm of sexism in society: Victimization and its discontents. Women's Stud Int Q 2:347-357

Bradley D, Walker N, Wilkie R (1986) Managing the police: law, organisation and democracy. Wheatsheaf, Brighton, UK 
Brown JM, Campbell EA (1994) Stress and policing: sources and strategies. John Wiley, Chichester

Brown J, King J (1998) Gender differences in police officers attitudes towards rape: Results of an exploratory study. Psychol. Crime Law 4:265-279

Burt MR (1980) Cultural myths and support for rape. J Pers Soc Psychol 38:217-230

Callan H (1989) Cultural factors in occupational stress. In Brown JM, Forde P (eds) Sources of non-traumatic stress in the police service. London: Police Requirements Support Unit, Home Office

Campbell R (1995) The role of work experience and individual beliefs in police officers' perceptions of date rape: An integration of quantitative and qualitative methods. Am J Community Psychol 23(2):249-277

Campbell R, Johnson CR (1997) Police officers' perceptions of rape: Is there consistency between state law and individual beliefs? J Interpers Violence 12(2):255-274

Carter DL, Sapp AD (1990) Higher education as a policy alternative to reduce police liability. Police Liabil Rev 2:1-3

Cohen B, Chaiken JM (1972) Police background characteristics and performance. Rand Institute, New York

Connell RW (1987) Gender and power. Polity, Cambridge

Connell RW (1995) Masculinities. University of California Press, Los Angeles 
Connell RW (2002) Gender (Short Introductions). Polity Press, Cambridge, UK

Daum J, Johns C (1994) Police work from a woman's perspective. The Police Chief 61:46-69

Feldman-Summers S, Palmer GC (1980) Rape as viewed by judges, prosecutors, and police officers. Crim Justice Behav 7(1):19-40

Field HS (1978) Attitudes toward rape: A comparative analysis of police, rapists, crisis counselors, and citizens. J Pers Soc Psychol 36(2):156-179

Fielding N (1994) Cop canteen culture. In Newburn TA, Stanko EA (eds) Just boys doing business? men, masculinities and crime. Routledge, London

Frewin K, Tuffin K (1998) Police status, conformity and internal pressure: A discursive analysis of police culture. Discourse Soc 9(2):173-185

Galton ER (1975) Police processing of rape complaints: A case study. Am J Crim Law 4(1):1530

Gottesman ST (1977) Police attitudes toward rape before and after a training program. J Psychiatr Nurs Ment Health Serv 15:14-18

Hazelwood RR, Burgess AW (eds) (1995) Practical Aspects of Rape Investigation: A Multidisciplinary Approach, 2nd ed. CRC Press, New York

Herbert S (1997) Policing space: territoriality and the Los Angeles police department. University of Minnesota Press, Minneapolis, MN 
Herbert S (1998) Police subculture reconsidered. Criminology 36(2):343-369

Holdaway S (1983) Inside the British Police: a force at work. Basil Blackwell, Oxford

Johnson BE, Kuck DL, Schander PR (1997) Rape myth acceptance and sociodemographic characteristics: A multisimensional analysis. Sex Roles 36(11/12):693-707

Kopper BA (1996) Gender, gender identity, rape myth acceptance, and time of initial resistance on the perception of acquaintance rape blame and avoidability. Sex Roles 34(1/2):81-93

Krimmel JT (1996) The performance of college-educated police: A study of self-rated police performance measures. Am J Police 15:85-96

LaFree GD (1989) Rape and criminal justice: the social construction of sexual assault. Wadsworth Publishing, Belmont, CA

LeDoux JC, Hazelwood RR (1985) Police attitudes and beliefs toward rape. J Police Sci Adm 13(3):211-220

Lersch KM, Kunzman LL (2001) Misconduct allegations and higher education in a southern sheriff's department. Am J Crim Justice 25(2):161-172

Lonsway KA, Welch S, Fitzgerald LF (2001) Police training in sexual assault response: Process, outcomes, and elements of change. Crim Justice Behav 28(6):695-730

Martin S (1989) Women in policing: The eighties and beyond. In Kenney D (ed.) Police and policing contemporary issues. Praeger, New York 
McNamara RP (1999) The socialization of the police. In Kenney DJ, McNamara RP (eds.) Police and policing: contemporary issues, 2nd ed. Praeger, Westport, CT

Messerschmidt JW (2000) Nine lives: adolescent masculinities, the body, and violence. Westview Press, Boulder, CO

Mori L, Bernat JA, Glenn PA, Selle LL, Zarate MG (1995) Attitudes toward rape: Gender and ethnic differences across Asian and Caucasian college students. Sex Roles 32(7/8):457-467

Mottaz C (1983) Alienation among police officers. J Police Sci Adm 11:23-30

Muram D, Hellman R, Cassinello B (1995) Prevalence of negative attitudes among police officers toward rape victims. Adolesc Pediatr Gynecol 8(2):89-91

Murrell ME, Lester D (1979) Masculinity in police officers. Psychol Rep 44:14

Roberg RR (1978) An analysis of the relationships among higher education, belief systems, and job performance of patrol officers. J Police Sci Adm 6:336-344

Roberg RR, Laramy JE (1980) An empirical assessment of the criteria utilized for promoting police personnel: a secondary analysis. J Police Sci Adm 8:183-187

Roberg R, Crank J, Kuykendall J (2004) Police and society, 2nd edn. Roxbury, Los Angeles, CA

Sanderson BB (1978) Police officers: The relationship of college education to job performance. The police chief 44:62

Schein E (1992) Organizational culture and leadership. Joey Bass Publishers, San Francisco, CA 
Schulhofer SJ (1988) Criminal justice discretion as a regulatory system. J Legal Stud 17:43-82

Scott MB, Lyman SM (1968) Accounts. Am Sociol Rev 33:46-62

Smith SM, Aamodt MG (1997) The relationship between higher education, experience, and police performance. J Police Crim Psychol 12:7-14

Smith AB, Locke B, Walker WF (1968) Authoritarianism in police college students and nonpolice college students. J Crim Law Criminol Police Sci 59:440-443

Smith AB, Locke B, Fenster A (1970) Authoritarianism in policemen who are college graduates and non-college graduates. J Crim Law Criminol Police Sci 61:313-315

Spence JT, Helmreich R, Stapp J (1973) A short version of the Attitudes Toward Women Scale (AWS). Bull Psychon Soc 2:219-220

Stanko EA (1997) Safety talk: Conceptualizing women's risk assessment as a 'technology of the soul'. Theor Criminol 1(4):479-499

Timmins WM, Hainsworth BE (1989) Attracting and retaining females in law enforcement. Int J Offender Ther Comp Criminol 33:197-205

Truxillo DM, Bennett SR, Collins ML (1998) College education and police job performance: a ten year study. Public Pers Manage 27(2):269-280 
Tyre M, Braunstein S (1992) Higher education and ethical policing. FBI Law Enforc Bull, June:6-10

U.S. Department of Justice, Bureau of Justice Statistics (2006) Law enforcement management and administrative statistics: local police departments, 2003. U.S. Department of Justice, Washington, D.C.

Ward C (1995) Attitudes toward rape: feminist and social psychological perspectives. Sage, London

Weiner N (1976) The educated policeman. J Police Sci Adm, December:450-457

Weirman CL (1978) Variances of ability measurement scores obtained by college and noncollege educated troopers. The Police Chief 45:34-36

Wilson H (1999) Post-secondary education of the police officer and its effect on the frequency of citizen complaints. Journal of California Law Enforcement 33:3-10

\section{Footnotes}

1 It was later discovered that at least two of the four police departments that declined participation had launched sexual assault or domestic violence investigations against a police officer within the department. 